\title{
Premarital sexual practice and its associated factors in Ethiopia. A systematic review and meta- analysis
}

Temesgen Getaneh ( $\nabla$ temugetaneh@gmail.com )

Debre Markos University

\section{Ayenew Negesse}

Debre Markos University

Jemberu Chane

Jigjiga University

Research article

Keywords: Pooled, Premarital, Sexual, Practice, Prevalence, Ethiopia

Posted Date: September 27th, 2019

DOI: https://doi.org/10.21203/rs.2.15254/v1

License: (c) (i) This work is licensed under a Creative Commons Attribution 4.0 International License.

Read Full License 


\section{Abstract}

Background Globally, large numbers of adolescents engage in premarital sexual practice. Youths who begin early sexual activity are more likely to be exposed for high-risk of having multiple sexual partners, infection with Human Immune Deficiency Virus (HIV) and other sexual transmitted diseases. There are pocket studies which reported meager and fragmented evidences across different parts of Ethiopia related with this issue, hence the aim of this review was also to estimate those meager evidences and come up with concrete information at the national level.

Methods articles were retrived through search engines such as: PubMed/MEDLINE, EMBASE, CINAHL, Google Scholar, HINARI portal, and Cochrane Library using the preferred Reporting Items for Systematic Reviews and Meta-Analyses Protocols (PRISMA-P) guidelines. Joanna Briggs Institute Meta-Analysis of Statistics Assessment and Review Instrument (JBI-MAStARI) was used for critical appraisal of the included articles. Random effect model analysis technique was considered to estimate the pooled prevalence of premarital sexual practice with their respective odds ratio (OR) and $95 \%$ confidence interval (Cl). Cochran's Q statistic, Egger's and Begg's test and meta regression were carried out to assess heterogeneity, publication bias and to identify associated factors respectively.

Results Exactly 24 articles with total sample size 14,872 individuals were included for this review. The pooled estimate of premarital sexual practice at the national level was 30.98\% (95\% Cl: 26.74, 35.21). Being female sex $(\mathrm{OR}=1.55$ : $95 \% \mathrm{Cl} ; 1.01,2.37)$, age $>18 y r s(\mathrm{OR}=2.39$ : 95\% $\mathrm{Cl} ; 1.29,4.42)$, being alcohol abuser with $(\mathrm{OR}=3.47 ; 95 \% \mathrm{Cl} ; 1.94,6.19)$ and exposed to pornography $(\mathrm{OR}=3.24: 95 \% \mathrm{Cl} ; 1.95,5.38)$ were the associated factors of premarital sexual practice in Ethiopia.

Conclusion The pooled prevalence of premarital sexual practice in Ethiopia was high in comparison with other countries. So that it is the strong recommendations of the authors' to provide an integrated youth's reproductive and sexual health services on the local context to decrease their exposure for premarital sexual practices and its negative impact on future life opportunities. Keywords: Pooled; Premarital; Sexual; Practice; Prevalence; Ethiopia .

\section{Background}

Marriage and sexual activity help to determine the extent to which women are exposed to the risk of pregnancy. However, the timing and circumstances of marriage and sexual activity also have profound consequences for women's and men's lives[1].

Globally, large number of adolescents engage in premarital sexual practice[2, 3]. As they are so young and less likely to use condom, unprotected or unsafe sexual practice is high $[4,5]$. Among youths who practiced premarital sexual practice, only very few numbers were continued as husband later on, while majority had sex with love even end up with prostitute[6]. Youths who begin early sexual activity are more likely to be exposed for high-risk of having multiple sexual partners[3, 7]. 
Premarital sexual practice among youth has a number of adverse effects and consequences interlinked with sexual and reproductive problems. Of which, early sexual debut increases young peoples' risk for infection with HIV and other STIs[7, 8], greater risk of unwanted pregnancy and prone for termination of the pregnancy through induced abortion[9]. All those complicated situations in turn increases the burden of maternal mortality and morbidity[10,11]. Moreover, it is also causes regrets, loss of self-respect, loss of family support, depression and victims to rituals among others[12].

In Ethiopia, the median age at first sexual intercourse is 0.5 years earlier than the median age at first marriage, which also indicates that both women and men engage in sex before marriage. Conversely, this increases the incidence of morbidity and mortality for both the mother and the child as a result of teenage pregnancy $[1,13,14]$. Giving birth during adolescence is known to have adverse social consequences in particular of poor educational attainment and early drop out of school $[1,8,12,15]$. Involvement in gang activities, drinking, smoking, living in low cost housing, dropping out of school, previously sexually abuse, peer pressure and having friends were explored as factors of premarital sexual practice $[10,16,17]$.

In Ethiopia different pocket studies assessed the premarital sexual practice and associated factors [5, 9, 11, 18-39]. However, the reports from those pocket studies on premarital sexual practice were represented with inconclusive and inconsistent findings. Hence the aim of this review was also to estimate those meager evidences and come up with concrete information at the national level.

\section{Methods}

\section{Searching strategies}

To identify articles, a comprehensive search of PubMed/MED LINE, EMBASE, CINAHL, Google Scholar, HINARI portal (which includes the SCOPUS, African Index Medicus, and African Journals Online databases), and Cochrane Library was carried out. The following searching terms were applied for PubMed advanced search: prevalence, practice, premarital sex, associated factors, risk factors, predictors and Ethiopia using OR, AND bullets. In addition, studies found on local shelves and institutional repositories were considered. The reference lists of already identified studies were screened to retrieve additional articles. The review was reported using the Preferred Reporting Items for Systematic Reviews and Meta-Analyses Protocols (PRISMA-P) checklist guidelines[40] (additional file-1). Articles conducted till July 30, 2019 on premarital sexual practice in Ethiopia were included in this meta-analysis. Endnote citation manager software version $\mathrm{X} 7$ for Windows was utilized to collect and organize search outcomes and for removal of duplicate articles.

\section{Inclusion criteria}

Population: studies conducted on unmarried women were included. 
Study area: the review considered only studies conducted in Ethiopia.

Language: articles reported in English language were eligible for this systematic review and metaanalysis. All available studies were included without restricting to a specific study design. In addition, predictors were taken as an exposure and premarital sexual practice as final outcome.

\section{Exclusion criteria}

After careful reviewing of the searched articles, irrelevant studies and those didn't report outcome of interest were excluded from this systematic review and meta-analysis. In addition, during the article selection process, studies, which were not fully accessible (full text

available), were excluded. However, before excluding the articles, we attempted to contact the primary author at least two times through email.

\section{Outcome of interest}

The outcome of this systematic review and meta-analysis was to estimate the pooled prevalence of premarital sexual practice in Ethiopia. In addition, we identified factors associated with premarital sexual practice. From those studies factors such as; sex of the participant (male $v_{s}$ female), resident (urban $v_{s}$ rural), age (<18yrs $v_{s} \geq 18 y r s$ ), pornography film (yes $v_{s} n o$ ), alcohol (yes $v_{s}$ no) and living alone or with family were considered to estimate the association factors.

\section{Data extraction}

Two authors (TG and AN) extract the data independently using the excel spreadsheet extraction tool. Authors, Region, study setting, study year, study design, sample size, response rate, participant's mean age, and prevalence for the primary outcome of interest and common associated factors extracted using two by two tables and logs odds ratio for each factors for our secondary outcome of interest were computed in the extraction tool. Discrepancies between authors were discussed to reach consensus. For final analysis the authors considered articles which fulfilled the already settled criteria.

\section{Quality assessment}

The database search results were exported and duplicate articles were removed using EndNote software (version X7; Thomson Reuters, New York, NY). We used the Newcastle-Ottawa quality assessment scale adapted for cross-sectional studies [41, 42]. The scale is used to score the articles under three categories:

- Selection (score 0-5);

- Comparability (score 0-2); and 
- Outcome (score 0-3); total score range 0-10.

The first section scored focuses on the methodological quality of each study (i.e., sample size, response rate, and sampling technique). The second section of the tool considers the comparability of different outcome groups in the study based on the study design and analysis. The last section deal about the outcomes and statistical analysis of the original study. Two authors (TG and AN) gave score for each primary studies. The third author was considered in case of disagreement. Then studies with a score of $\geq 6$ out of 10 were considered as high quality after reviewing different relevant literatures. Identified articles with methodological problems and incomplete reporting of results in the full text were excluded from this systematic review and meta-analysis (additional file 2).

\section{Data analysis}

Information computed from retrieved articles was extracted using Microsoft Excel spreadsheet form and exported to STATA (version 14; Stata Corp, College Station, TX) for further analysis. Cochran's Q statistic was quantified using inverse variance $\left(\mathrm{I}^{2}\right)$ with their corresponding $\mathrm{p}$-value. Heterogeneity was considered when p-value less than 0.05 . A value of $25 \%, 50 \%$, and $75 \%$ were used to declare the heterogeneity test as low, medium and high heterogeneity[43]. In addition, publication bias was checked using Egger's and Begg's tests[44, 45] and a p-value less than 0.05 were considered as statistically significance. The estimated pooled prevalence of premarital sexual practice was computed using forest plots with the $95 \% \mathrm{Cl}$. Odds ratio was considered as measure of association to identify the factors associated with premarital sexual practice in Ethiopia.

\section{Results}

A total of 230 articles were searched using electronic data base of which 50 articles were removed due to duplication. From the remaining articles, 151 studies were excluded because of irrelevancy. Finally 5 articles [36, 46-49] were removed as a reason of inaccessible of its full documents. Finally, 24 articles were included for the final systematic review and meta-analysis (figure-1).

Figure 1: PRISMA flow diagram of included studies to estimate the pooled prevalence of premarital sexual practice and its associated factors in Ethiopia 2006-2018

\section{Characteristics of the primary articles}

A total of twenty four articles met the inclusion criteria and a total of 14,872 male and female participants were considered for final analysis. All the included studies were done through cross sectional study design with an estimated sample size range from 207[31] up to 2,880[29] taken from Addis Ababa in 2013 and Oromia region in 2011 respectively. 
Of the included articles, $41.6 \%$ of the included studies were conducted from Oromia region[5, 11, 18,24 , 29, 33, 35, 37-39]: seven studies from Amhara region[19-22, 28, 30, 34]: four studies were reported from SNNPR $[9,26,27,32]$ : two articles in Tigray[23, 25] and one articles[31] conducted in Addis Ababa city administration. Except one study which was conducted at community level in Tigray region[23], all other studies were done at the institutional level. After critical appraisal of each articles based on NewcastleOttawa quality assessment scale, both in peer and independently, each studies scored in the range of 6up to 9 values.

Table 1: Descriptive summary of 24 studies included in the meta-analysis of premarital sexual practice and associated factors in Ethiopia 2006-2018

\begin{tabular}{|l|l|l|l|r|r|l|}
\hline Author name & $\begin{array}{l}\text { Study } \\
\text { year }\end{array}$ & Region & $\begin{array}{l}\text { Mean } \\
\text { age }\end{array}$ & $\begin{array}{l}\text { Sample } \\
\text { Size }\end{array}$ & $\begin{array}{l}\text { Prevalence } \\
(\%)\end{array}$ & $\begin{array}{l}\text { Quality } \\
\text { score }\end{array}$ \\
\hline Sendo et al [31] & 2013 & AA & 21.8 & 207 & 60.9 & 6 \\
\hline Akibu et al[19] & 2016 & Amhara & 18.7 & 604 & 54.3 & 7 \\
\hline Oljira et al[29] & 2011 & Oromo & 17.1 & 2880 & 24.8 & 9 \\
\hline Tesfaye et al[5] & 2014 & Oromo & 21 & 704 & 30 & 8 \\
\hline Teferra et al[35] & 2013 & Oromo & 18.4 & 324 & 42.7 & 7 \\
\hline Seme et al[38] & 2006 & Oromo & 16 & 722 & 21.5 & 8 \\
\hline Taye et al[33] & 2014 & Oromo & 17 & 352 & 25.4 & 6 \\
\hline Bogale et al[22] & 2012 & Amhara & 16.48 & 826 & 19 & 7 \\
\hline Taye B et al[34] & 2016 & Amhara & 20 & 352 & 23.3 & 6 \\
\hline Sorato et al[32] & 2015 & SNNPR & 21.25 & 575 & 43.1 & 6 \\
\hline $\begin{array}{l}\text { Mengistie et } \\
\text { al[27] }\end{array}$ & 2014 & SNNPR & 22 & 372 & 35.6 & 8 \\
\hline Kassa et al [13] & 2013 & Tigray & 16.7 & 493 & 21.1 & 7 \\
\hline Arega et al[20] & 2017 & Amhara & 17 & 497 & 22.5 & 9 \\
\hline Behulu et al[21] & 2017 & Amhara & 17.31 & 624 & 31.3 & 7 \\
\hline Hurissa et al[24] & 2013 & Oromo & 17.75 & 358 & 39.7 & 7 \\
\hline $\begin{array}{l}\text { Mulugeta et al } \\
\text { [28] }\end{array}$ & 2012 & Amhara & 18.17 & 1123 & 30.8 & 9 \\
\hline Abdisa et al[11] & 2015 & Oromo & 20.9 & 650 & 25.7 & 8 \\
\hline Tololu et al[37] & 2016 & Oromo & 21 & 422 & 31.9 & 7 \\
\hline Endalew et al[39] & 2015 & Oromo & - & 702 & 20.6 & 7 \\
\hline $\begin{array}{l}\text { Gebreyesus } \text { et } \\
\text { al[23] }\end{array}$ & 2018 & Tigray & 17.4 & 536 & 47.6 & 7 \\
\hline Habte et al[30] & 2017 & Amhara & 17.51 & 284 & 32.6 & 6 \\
\hline Abate et al[18] & 2015 & Oromo & 17.8 & 532 & 21 & 7 \\
\hline Meleko et al[26] & 2017 & SNNPR & - & 320 & 25.2 & 6 \\
\hline $\begin{array}{l}\text { Tekletsadik et } \\
\text { al[9] }\end{array}$ & 2013 & SNNPR & 16.4 & 413 & 18.3 & 7 \\
\hline
\end{tabular}

\section{Prevalence of premarital sexual practice in Ethiopia}

As shown on forest plot below, the pooled prevalence of premarital sexual practice in Ethiopia was $30.98 \%$ (95\% Cl: $26.74,35.21)$. The heterogeneity test showed substantially significant $\left(\mathrm{I}^{2}=90 \%, p<0.001\right)$ 
indicating that random effect model is best fitted for this data. So this indicated the need for subgroup analysis which demands identifying the sources of heterogeneity (figure-2).

\section{Sub group analysis}

Since, this review is exhibited with substantial heterogeneity, subgroup analysis based on study region, study year, participants mean age and sample size were considered to identify possible source of heterogeneity across studies (table-2). However the subgroup analysis indicated that the possible source of heterogeneity was not due to study region, study year, participants mean age and sample size they used. In addition publication bias was assed using Egger's and Begg's tests and the value significant at pvalue of 0.021 and 0.004 respectively.

Figure 2: Forest plot of the pooled prevalence of premarital sexual practice in Ethiopia 2006-2018

So that the trim fill meta-analysis[50]was done to account for the publication bias. Based on this analysis, the prevalence of premarital sexual practice was $30.98 \%(95 \% \mathrm{Cl}: 26.74,35.21)$ and no significant change was exhibited as compared with the main meta-analysis.

\section{Meta regression}

In addition to subgroup analysis and publication bias, Meta regression was also assumed by considering both continuous and categorical data to identify associated factors of heterogeneity for the pooled prevalence of premarital sexual practice.

Table 2: Sub group analysis which describes pooled prevalence of premarital sexual practice and its predictors in Ethiopia from 2006-2018 


\begin{tabular}{|l|l|l|l|l|l|l|}
\hline Subgroup & & $\begin{array}{l}\text { No of } \\
\text { studies }\end{array}$ & $\begin{array}{l}\text { prevalence } \\
(95 \% c i)\end{array}$ & $\begin{array}{l}\text { Heterogeneity } \\
\text { statistics }\end{array}$ & $\mathrm{I}^{2}$ & p-value \\
\hline \multirow{4}{*}{ Region } & Oromo & 10 & $27.71(21,34)$ & 92.23 & 94.6 & $<0.001$ \\
\cline { 2 - 7 } & Amhara & 7 & $31.44(21,41)$ & 46.58 & 95.7 & $<0.001$ \\
\cline { 2 - 7 } & SNNPR & 4 & $39.50(28,50)$ & 292.64 & 99.0 & $<0.001$ \\
\cline { 2 - 7 } & Others & 3 & $27.40(16,38)$ & 19.12 & 94.8 & $<0.001$ \\
\hline \multirow{2}{*}{$\begin{array}{l}\text { Study } \\
\text { year }\end{array}$} & $\begin{array}{l}\text { 2014\& } \\
\text { below }\end{array}$ & 12 & $30.60(24,36)$ & 126.37 & 91.3 & $<0.001$ \\
\cline { 2 - 7 } & $>2014$ & 12 & $31.38(25,37)$ & 103.53 & 89.4 & $<0.001$ \\
\hline \multirow{2}{*}{ Mean age } & $\leq 18$ & 14 & $26.83(25,37)$ & 72.51 & 84.8 & $<0.001$ \\
\cline { 2 - 7 } & $>18$ & 10 & $37.65(30,44)$ & 97.61 & 90.4 & $<0.001$ \\
\hline \multirow{2}{*}{$\begin{array}{l}\text { Sample } \\
\text { size }\end{array}$} & $\leq 500$ & 12 & $31.39(25,37)$ & 142.37 & 95.8 & $<0.001$ \\
\cline { 2 - 7 } & $>500$ & 12 & $30.59(24,36)$ & 1085.64 & 99.4 & $<0.001$ \\
\hline
\end{tabular}

Sample size, study year, study region and mean age were considered in the meta-regression. However, the meta-regression indicated that the pooled prevalence of premarital sexual was not associated with study year, sample size, study region and mean age (Table-3).

\section{Associated factors of premarital sexual practices in Ethiopia}

Alcohol drinking, being female, age $>18 y$ rs and viewing pornography were found to have significant association with premarital sexual practice while living alone and living in urban areas were not associated with premarital sexual practice.

The association between sex and premarital sexual practice was reported in 14 primary articles. The odds of practicing premarital sex were 1.55 times higher among female individuals compared with male individuals with $\mathrm{OR}=1.55,(95 \% \mathrm{Cl} ; 1.01,2.37)$. The effect of age on pooled prevalence of premarital sexual practice was evaluated using 11 original articles. Individuals with age >18yrs were 2.39 times more likely to have premarital sexual practice than individuals with age $\leq 18 \mathrm{yrs}$ with $\mathrm{OR}=2.39,(1.29$, 4.42). More than 10 articles on premarital sexual practice estimated the relation between alcohol and premarital sexual practice. The odds of having premarital sexual practice were 3.47 times higher among alcohol drinker than compared to non-alcohol drinker individuals with $\mathrm{OR}=3.47$, $(95 \% \mathrm{Cl} ; 1.94,6.19)$. The other significantly associated factor was viewing sex film (pornography) which was reported in $45 \%$ of original articles. The likely hood of premarital sexual practice among those individuals viewing pornography (sex film) was 3.24 times higher than those not seen pornography with $\mathrm{OR}=3.24$, $(95 \% \mathrm{Cl}$; $1.95,5.38$ ) (figure -3 and figure -4 ).

Table 3Meta regression for the included studies to identify source of heterogeneity for the prevalence of premarital sexual practice in Ethiopia from 2006- 2018 


\begin{tabular}{|c|c|c|}
\hline Variables & Coefficients & p-value \\
\hline Study year & 0.92 & 0.32 \\
\hline Sample size & -0.004 & 0.32 \\
\hline Mean age & 2.81 & 0.27 \\
\hline \multicolumn{3}{|l|}{ Region } \\
\hline Oromo & Reference & Reference \\
\hline Amhara & 2.27 & 0.41 \\
\hline $\begin{array}{l}\text { SNNPR } \\
\text {. }\end{array}$ & 2.03 & 0.35 \\
\hline Others & 14.58 & 1.96 \\
\hline
\end{tabular}

Figure-3 Forest plots which describe factors associated with premarital sexual practice in Ethiopia 2006-2018

\section{Discussion}

This systematic review and meta-analysis was done to estimate the pooled prevalence of premarital sexual practice and its associated factors in Ethiopia from 2006 up to 2018. Although premarital sex is socially unacceptable in Ethiopia[1], the review has shown that the proportion of individuals having sexual intercourse before marriage is considerably high. Due to the sensitive nature of the issue[51], this proportion may still be under-reported. The review revealed that nearly one third of youths practiced premarital sex in Ethiopia. The new generation seems more open towards premarital sexual activities. Young age is more liberal towards their sexual behaviors[17].

Adolescent finds the way to break conventional obstacles and looks for the information by themselves on the issues which have significant influence in their life as well on their sexuality[52]. The prevalence of premarital sexual practice in this systematic review and meta-analysis was lower than findings of the study conducted in China, Nepal and Nigeria [2, 3, 53]. This systematic review and meta-analysis was also reported a more prevalent estimate compared with a study conducted in India and Vietnam [6, 7]conducted on school youths. Figure4 Forest plots which describe factors associated with premarital sexual practices in Ethiopia 2006-2018

Even though cultural beliefs discourage premarital sexual practices[27], Ethiopian women exposed to risk of sexual practice and pregnancy earlier[1]. This systematic review and meta-analysis also indicated that exposing to pornography, alcohol drinking, being female and age more than 18 years were found to be significantly associated with premarital sexual practice in Ethiopia. Individuals who had exposed pornography film were more likely to have premarital sexual practice than those didn't exposed pornography. They may watch pornographic films to fulfill their desires to learn about sexual issues and may get opportunity like out of family supervision and stimulate sexual desires. Consistent findings were also reported from Asian countries and Vietnam[6, 10]. Late age youths (age more than 18yrs) were more likely to experience premarital sexual practice than early age youths (age less than 18yrs). In line with this systematic review and meta-analysis, a report from Nepal[54] also reported that youths of age 20-24yrs were more likely to expose for premarital sexual practice than youths age from 18-19yrs. 
Moreover, the likelihood of premarital sexual practice among female was higher, when compared with male counterparts. This is because the effect of culture forces females to be exposed towards premarital sex than their male counterparts and most girls have a belief that they become ready to do anything to make their love succeed[17]. In contrast to the report from this systematic review and meta-analysis, studies from Nepal and Vietnam showed male were more likely to be involved in premarital sex than female[4, 6, 54], because mostly men have freedom to decide on major tasks in their life.

Once more, similar with the reports from Asian countries and Nepal[10,54], Youths who drink alcohol were more likely get involved in premarital sexual practice than those who didn't drink alcohol. This can be possibly explained by that risky sexual behavior such as smoking and alcohol drinking is associated with higher approval of premarital sexual practice $[5,6,17]$.

\section{Conclusion}

This systematic review and meta-analysis indicated a significant number of (30.98\%) youths practiced premarital sexual practice in Ethiopia. Predominate factors associated with premarital sexual practice were age greater than 18 , watching pornography, alcohol abusing and being female. Therefore, Minister of Health in collaborate with its stake holders should emphasis on integration reproductive and sexual health education in youths curriculum to increase knowledge and attitudes on sexuality and to prevent premarital sexual practice consequences.

\section{Abbreviations}

AA-Addis Ababa, HIV-Human Immuno Virus, SNNPR-South Nation and Nationality peoples Region, STIs-Sexual Transmitted Diseases

\section{Declarations}

\section{Acknowledgments}

Not applicable.

\section{Funding}

No funding was obtained for this study.

\section{Availability of data and materials}

Data will be available from the corresponding author upon reasonable request. 


\section{Authors' contributions}

TG developed the protocol and involved in the design, selection of study, data extraction, statistical analysis and developing the initial drafts of the manuscript. TG and AN involved in quality assessment. TG, AN and JC prepared and revising subsequent drafts as well as prepared the final draft of the manuscript. All authors read and approved the final draft of the manuscript.

\section{Ethics approval and consent to participate}

Not applicable.

\section{Consent for publication}

Not applicable.

\section{Competing interests}

The authors have declared that there are no competing interests.

\section{Publisher's Note}

Springer Nature remains neutral with regard to jurisdictional claims in published maps and institutional affiliations

\section{Author details}

${ }^{1}$ Department of Midwifery, College of Health Science, Debre Markos University, Debre Markos, Ethiopia

${ }^{2}$ Department of Nutrition, College of Health Science, Debre Markos University, Debre Markos, Ethiopia

${ }^{3}$ Department of Midwifery, College of Medicine and Health Science, Jigjiga University, Jigjiga, Ethiopia

\section{References}

1.FDRE: ETHIOPIA Demographic and Health Survey 2016.

2.Adhikari R, Tamang J: Premarital sexual behavior among male college students of Kathmandu, Nepal. BMC public health 2009, 9(1):241. 
3.Zhang L, Gao X, Dong Z, Tan Y, Wu Z: Premarital sexual activities among students in a university in Beijing, China. Sexually Transmitted Diseases 2002, 29(4):212-215.

4.Chihurumnanya A, Lawrence U, Benedict N, Uche D, Nnenna A: Premarital Sex, Safer Sex and Factors Influencing Premarital Sex Practices Among Senior Secondary School Students in Ebonyi Local Government Area of Ebonyi State Nigeria. J Community Med Public Health Care 2016, 3.012.

5.Regassa T, Chala D, Adeba E: Premarital sex in the last twelve months and its predictors among students of Wollega University, Ethiopia. Ethiopian journal of health sciences 2016, 26(4):351-358.

6.Le LC, Blum RW: Premarital sex and condom use among never married youth in Vietnam. In.: De Gruyter; 2009.

7.Dave VR, Makwana NR, Yadav BS, Yadav S: A study on high-risk premarital sexual behavior of college going male students in Jamnagar City of Gujarat, India. International journal of high risk behaviors \& addiction 2013, 2(3):112.

8.Ghebremichael MS, Finkelman MD: The effect of premarital sex on sexually transmitted infections (STIS) and high risk behaviors in women. Journal of AIDS and HIV research (Online) 2013, 5(2):59.

9.Tekletsadik E, Shaweno D, Daka D: Prevalence, associated risk factors and consequences of premarital sex among female students in Aletawondo High School, Sidama Zone, Ethiopia. Journal of Public Health and Epidemiology 2014, 6(7):216-222.

10.Wong M-L, Chan RK-W, Koh D, Tan H-H, Lim F-S, Emmanuel S, Bishop G: Premarital sexual intercourse among adolescents in an Asian country: multilevel ecological factors. Pediatrics 2009, 124(1):e44-e52.

11.Abdissa B, Addisie M, Seifu W: Premarital Sexual practices, consequences and associated factors among regular undergraduate female students in Ambo University, Oromia Regional State, Central Ethiopia, 2015. Health Science Journal 2017, 11(1):1.

12.Abdullahi M, Umar A: Consequences of pre-marital sex among the youth a study of University of Maiduguri. IOSR Journal of Humanities and Social Science 2013, 10(1):10-17.

13.Kassa GM, Arowojolu A, Odukogbe A, Yalew AW: Adverse neonatal outcomes of adolescent pregnancy in Northwest Ethiopia. PloS one 2019, 14(6):e0218259.

14.Neal S, Channon AA, Chintsanya J: The impact of young maternal age at birth on neonatal mortality: Evidence from 45 low and middle income countries. PloS one 2018, 13(5):e0195731.

15.Glynn JR, Sunny BS, DeStavola B, Dube A, Chihana M, Price AJ, Crampin AC: Early school failure predicts teenage pregnancy and marriage: A large population-based cohort study in northern Malawi. PloS one 2018, 13(5):e0196041. 
16.Mazengia F, Worku A: Age at sexual initiation and factors associated with it among youths in North East Ethiopia. Ethiopian Journal of Health Development 2009, 23(2).

17.Kassahun EA, Gelagay AA, Muche AA, Dessie AA, Kassie BA: Factors associated with early sexual initiation among preparatory and high school youths in Woldia town, northeast Ethiopia: a cross-sectional study. BMC public health 2019, 19(1):378.

18.Abate G: Premarital sexual practice and associated factors among preparatory school students in jimma town, oromia region, south west ethiopia. J Biol Agric Healthc 2016, 6.34-41.

19.Akibu M, Gebresellasie F, Zekarias F, Tsegaye W: Premarital sexual practice and its predictors among university students: institution based cross sectional study. Pan African Medical Journal 2017, 28(1).

20.Arega WL, Zewale TA, Bogale KA: Premarital sexual practice and associated factors among high school youths in Debretabor town, South Gondar zone, North West Ethiopia, 2017. BMC research notes 2019, $12(1): 314$.

21.Behulu GK, Anteneh KT, Aynalem GL: Premarital sexual intercourse and associated factors among adolescent students in Debre-Markos town secondary and preparatory schools, north west Ethiopia, 2017. $B M C$ research notes 2019, 12(1):95.

22.Bogale A, Seme A: Premarital sexual practices and its predictors among in-school youths of shendi town, west Gojjam zone, North Western Ethiopia. Reproductive health 2014, 11(1):49.

23.Gebreyesus H, Berhe T, Welegebriel Z, Wubayehu T, Hailemariam G, Gebrekirstos G, Teweldemedhin M: Premarital sexual practice and associated factors among adolescents in the refugee camps in Tigray, northern Ethiopia. BMC research notes 2019, 12(1):415.

24. Hurissa B, Tebeje B, Megersa H: Prevalence of Pre-marital Sexual Practices and Associated Factors among Jimma Teacher Training College Students in Jimma Town, south west Shoa Zone, Oromiya Region, Ethiopia-2013. J Women's Health Care 2014, 4(221):2167-0420.1000221.

25.Kassa GM, Woldemariam EB, Moges NA: Prevalence of premarital sexual practice and associated factors among alamata high school and preparatory school adolescents, Northern Ethiopia. Global Journal of Medical Research 2014.

26.Meleko A, Mitiku K, Kebede G, Muse M, Moloro N: Magnitude of Pre-marital Sexual Practice and its Associated Factors among Mizan Preparatory School Students in Mizan Aman Town, South West Ethiopia. J Community Med Health Educ 2017, 7(539):2161-0711.1000539.

27.Mengistie Z, Wolie E, Abawa E, Ebre E, Adera A: Knowledge attitude and practice towards premarital sex and HIV/AIDS among Mizan-Tepi University students, south west Ethiopia. Sci J public Health 2015, 3(4):592-599. 
28.Mulugeta Y, Berhane Y: Factors associated with pre-marital sexual debut among unmarried high school female students in bahir Dar town, Ethiopia: cross-sectional study. Reproductive health 2014, 11(1):40.

29.Oljira L, Berhane Y, Worku A: Pre-marital sexual debut and its associated factors among in-school adolescents in eastern Ethiopia. BMC public health 2012, 12(1):375.

30.Paul E, Msengwa A: Prevalence of premarital sexual practices and its associated factors among high school students in Addis Zemen Town South Gondar Ethiopia 2017. Journal of Public Health and Epidemiology 2018, 10(11):387-394.

31.Sendo EG: Premarital sexual practice among unmarried first year undergraduate students in Alkan University College in Addis ababa, Ethiopia. Global Journal of Medicine and Public Health 2014, 3(2):110.

32.Sorato M, Belijo Z: Magnitude and Predictors of Premarital Sexual Practice among Unmarried Undergraduate Students, at Arba Minch University, Ethiopia, 2015. Int J Reprod Fertil Sex Health 2017, $4(2): 95-104$.

33.Taye A, Asmare I: Prevalence of premarital sexual practice and associated factors among adolescents of Jimma Preparatory School Oromia Region, South West Ethiopia. J Nurs Care 2016, 5(2):353.

34.Taye B, Nurie T: Assessment of premarital sexual practices and associated factors among private college regular students in Bahir dar city, northwest Ethiopia: a cross-sectional study. Int J Hort Agric Food Sci 2017, 1:60-67.

35.Teferra TB, Erena AN, Kebede A: Prevalence of premarital sexual practice and associated factors among undergraduate health science students of Madawalabu University, Bale Goba, South East Ethiopia: institution based cross sectional study. Pan African medical journal 2015, 20(1).

36.Tilahun M, Ayele G: Factors associated with age at first sexual initiation among youths in Gamo Gofa, south west Ethiopia: a cross sectional study. BMC Public Health 2013, 13(1):622.

37.Tololu A, Belda S, Worku B: Premarital sexual practice and associated factors among robe TVET students at robe town, bale zone, Oromia region, southeast Ethiopia, 2016. MOJ Public Health 2017, 5(6):193-203.

38.Assefa s, Dessalegn W: premarital sexual practice among school adolescents in Nekemte Town, East Wolega 2006.

39.Duressa E, Gebremichael B, Mulugeta T, Tarekegn A: Premarital Sexual Practice and Risky Sexual Behaviors Associated with it among Secondary School Adolescents, South East Ethiopia: A Mixed Design Study. AIDS \& Clinical Research 2018, 9(9). 
40.A. Liberati, D. G. Altman, Tetzlaff J: "The PRISMA statement for reporting systematic reviews and meta-analyses of studies that evaluate health care interventions: explanation and elaboration," Journal of Clinical Epidemiology 2009, 62(10).

41.Herzog R, Álvarez-Pasquin MJ, Díaz C, Del Barrio JL, Estrada JM, Á G: Are healthcare workers' intentions to vaccinate related to their knowledge, beliefs and attitudes? A systematic review. BMC Public Health 2013, 13(1).

42.Wells G, Shea B, O'Connell D, Peterson J, Welch V, Losos M: The Newcastle-Ottawa (NOS) for assessing the quality of nonrandomized studies in meta-analysis. Ottawa: . Ottawa Hospital Research Institute 2017.

43. Huedo-Medina TB, Sánchez-Meca J, Marín-Martínez F, J. B: Assessing heterogeneity in meta-analysis: Q statistic or I $^{2}$ index? Psychological methods 2006, 11(2):193.

44.Begg Colin B, and Mazumdar Madhuchhanda: Operating characteristics of a rank correlation test for publication bias. Biometrics 1994:1088-1101.

45.Egger Matthias, Smith George Davey, and Schneider Martin et al: Bias in meta-analysis detected by a simple, graphical test. Bmj 1997, 315(7109):629-634.

46.A. M: Assessment of the prevalence of premarital sex andunprotected sexual practice among Gedeo zone high school students, SNNPR, Ethiopia. [Mph thesis]. Addis Ababa University; June, 2006.

47.Bane D: Assessment of premarital sexual practices and factors related to it among Ambo high school students. Addis Ababa University 2006.

48.Berihun H: Assessment of the Prevalence of Premarital Sex and Unprotected Sexual Practices among Secondary School Adolescent Students in Sebeta Town, Oromia Regional State, Ethiopia,. 2014.

49.Mekuria M: Premarital Sexual Practice and Perception of High Risk of HIV/AIDS among School Adolescents in Injibara Town, Awi Zone. Addis Ababa University; 2008.

50.Duval S, R. aT: Trim and fll: a simple funnel-plot-based method of testing and adjusting for publication bias in meta-analysis. Biometrics 2000, 56(2):455-463.

51.G D, F M: Assessing communication on sexual and reproductive health issues among high school students with their parents, Bullen Woreda, Benishangul Gumuz Region. North West Ethiop. Ethiop J Health Dev 2010, 24(2):89-95.

52.Sarah B, Shireen j, lqubal s: Towards adulthood Exploring the Sexual and Reproductive Health of adolescents in South Asia. WHO Geneva 2003. 
53.Jane OA, Ezenduka PO, Elkenah CN: Variables Influencing Premarital Sex among Secondary School Adolescents in Anambra State, Nigeria. Journal of Community \& Public Health Nursing 2017, 2.

54.Basel P: Premarital sex behaviors among college youths of Kathmandu, Nepal. Kathmandu University medical journal 2013, 11(1):27-31.

\section{Figures}
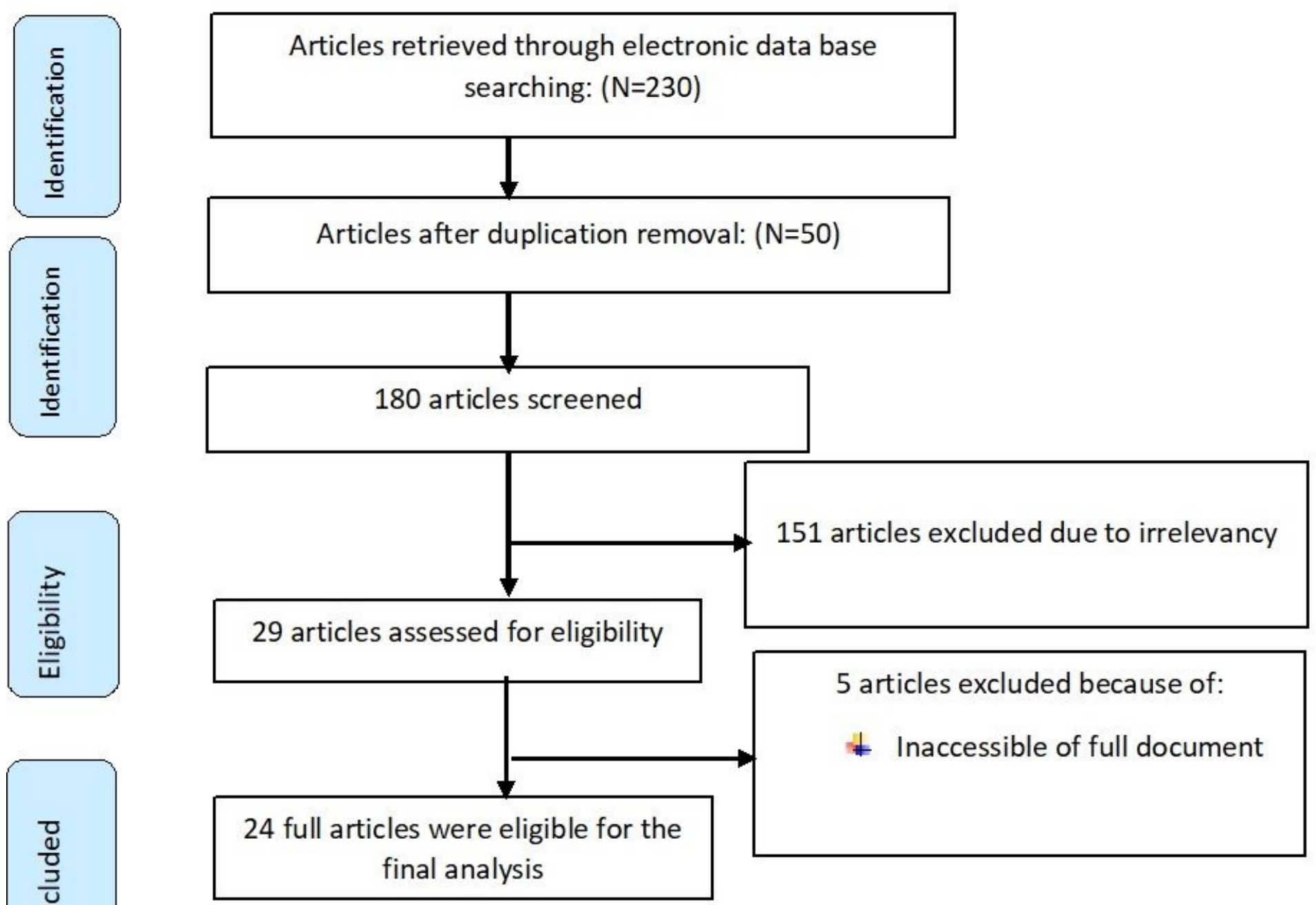

\section{Figure 1}

PRISMA flow diagram of included studies to estimate the pooled prevalence of premarital sexual practice and its associated factors in Ethiopia 2006-2018 


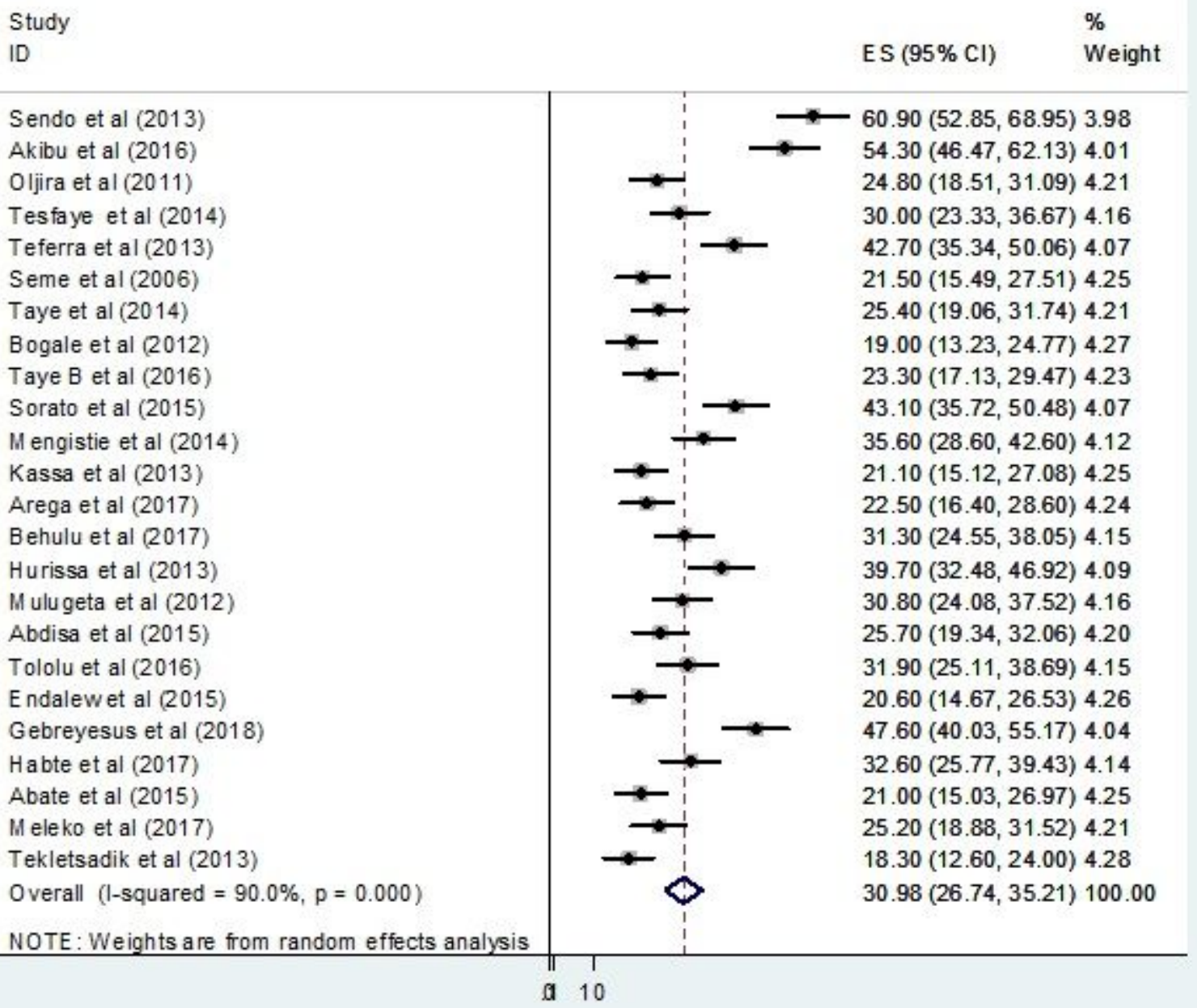

\section{Figure 2}

Forest plot of the pooled prevalence of premarital sexual practice in Ethiopia 2006-2018 


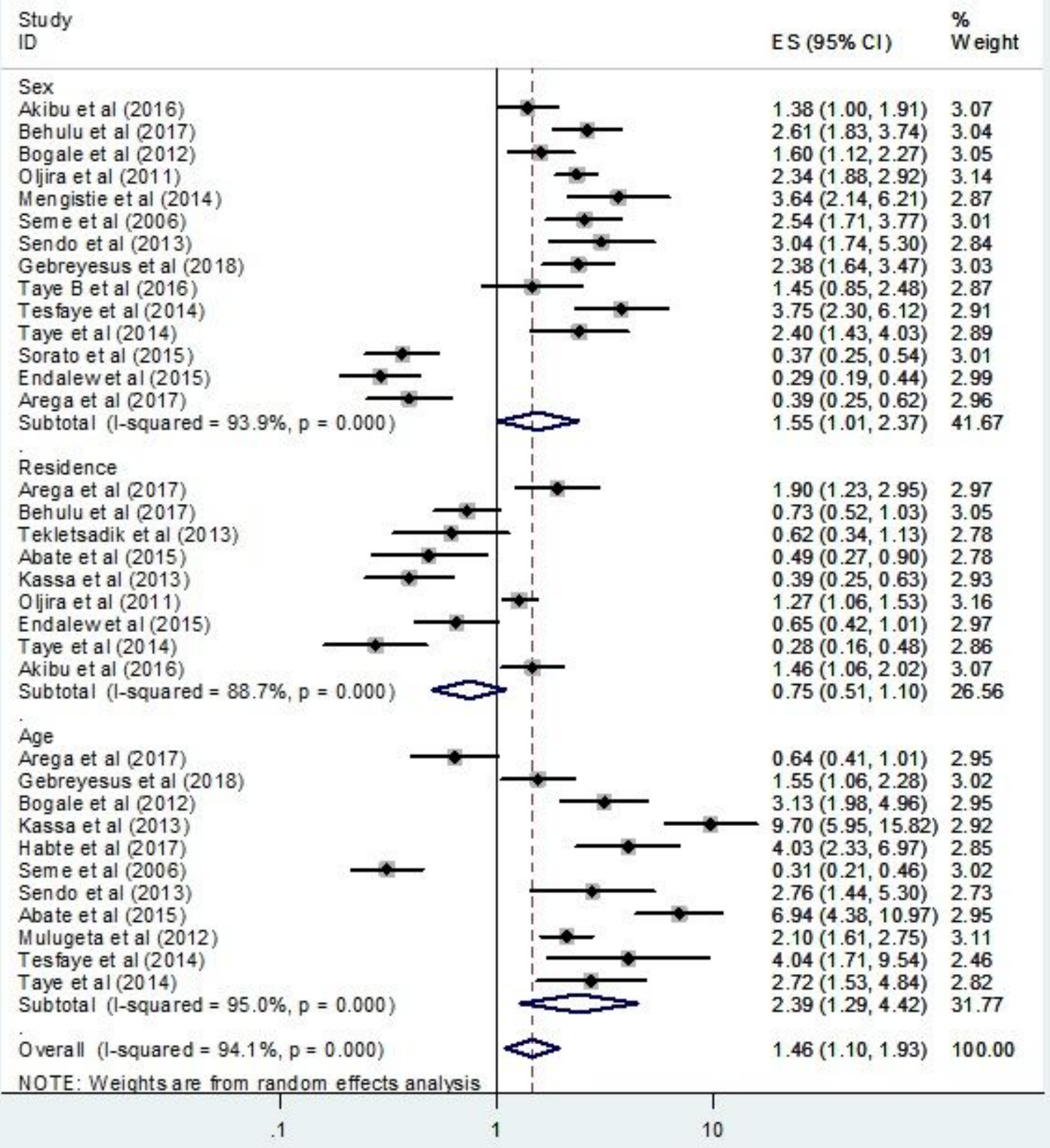

Figure 3

Forest plots which describe factors associated with premarital sexual practice in Ethiopia 2006-2018 


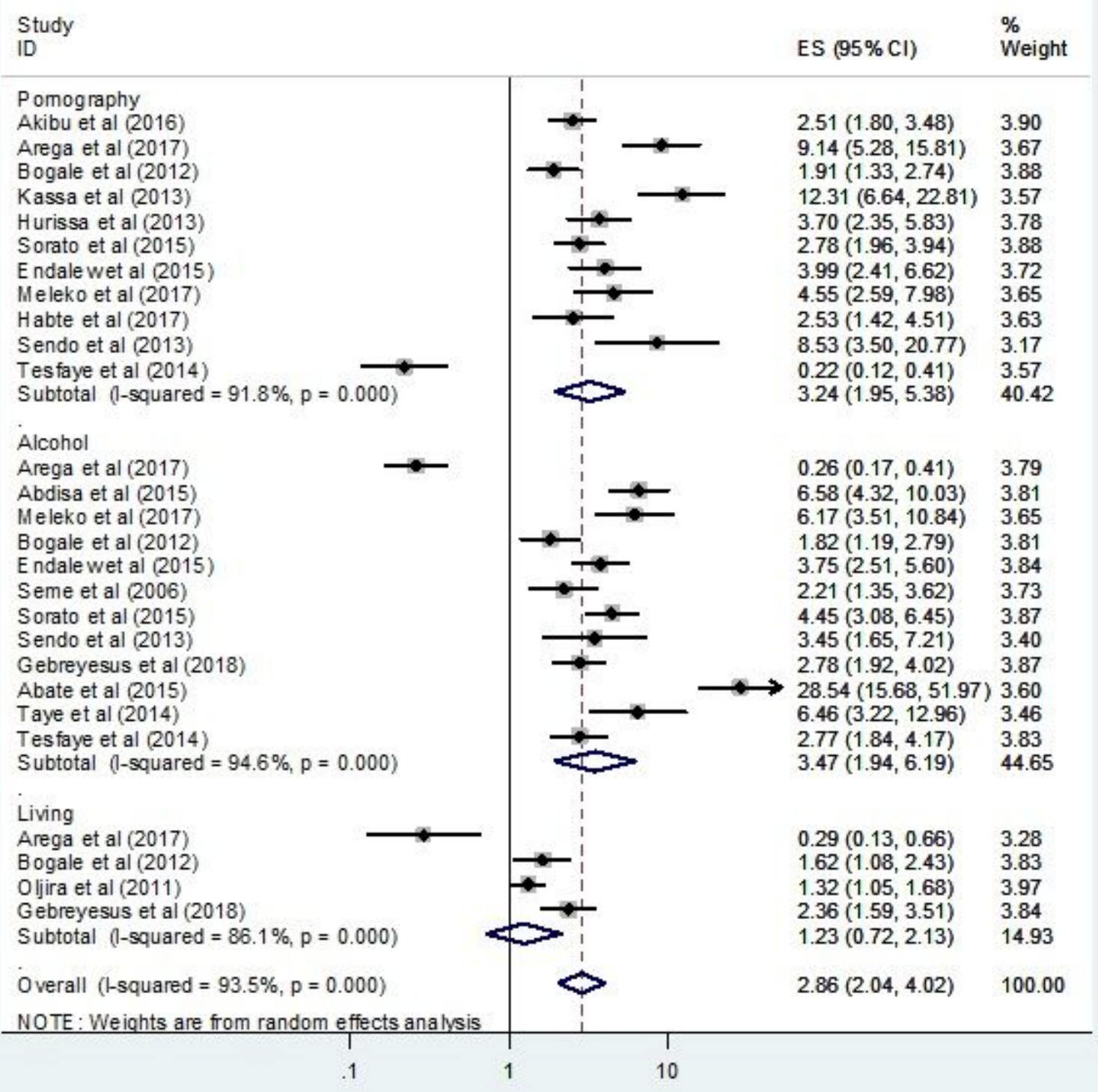

\section{Figure 4}

Forest plots which describe factors associated with premarital sexual practices in Ethiopia 2006-2018 